A 61-year-old man underwent partial hepatectomy for metastases in the left lateral lobe. One month later, he developed intermittent fever. Abdominal computed tomography (CT) revealed a fluid collection $4.5 \times 6.0 \mathrm{~cm}$ in size compressing the gastric wall (Figure $\mathbf{1}$ ).

Cholangiography revealed a leak from the peripheral left intrahepatic ducts. A 10-Fr transpapillary biliary stent $5 \mathrm{~cm}$ long was placed. Duodenoscopy was used to carry out transgastric drainage of the infected biloma. The extrinsic compression at the lesser curvature of the stomach was entered using the Seldinger technique without electrocautery or endoscopic ultrasound (EUS) guidance, as previously described for pseudocyst drainage [1]. The bulge in the stomach was punctured using a 19-gauge needle (BAN, WilsonCook Medical, Winston-Salem, North Carolina, USA). Purulent fluid was aspirated, and a 0.035 -inch guide wire was coiled within the cavity. The transgastric tract was dilated with a $4-\mathrm{mm}$ balloon, and a 10-Fr double pigtail stent $5 \mathrm{~cm}$ in length was placed within the cavity. There were no complications, and the patient was discharged home the following day.

A CT scan 1 month later demonstrated resolution of the biloma (Figure 2 ). The transgastric and transpapillary stents were removed. Cholangiography showed no biliary leakage. The patient was still well at the time of writing, 6 weeks later.

There has been one report of transgastric drainage of a biloma following laparoscopic cholecystectomy in which cholangiography did not reveal a bile leak [2]. The present case is the first report of endoscopic drainage of an infected biloma using a combination of the transmural and transpapillary techniques. Endoscopic transgastric drainage of fluid collections using EUS-guided approaches has been described for hepatic abscesses [3], subphrenic abscesses [4], and gallbladder fossa collections [5]. Transmural drainage should be considered as an alter-

\title{
Combined Endoscopic Transgastric and Transpapillary Drainage of an Infected Biloma
}

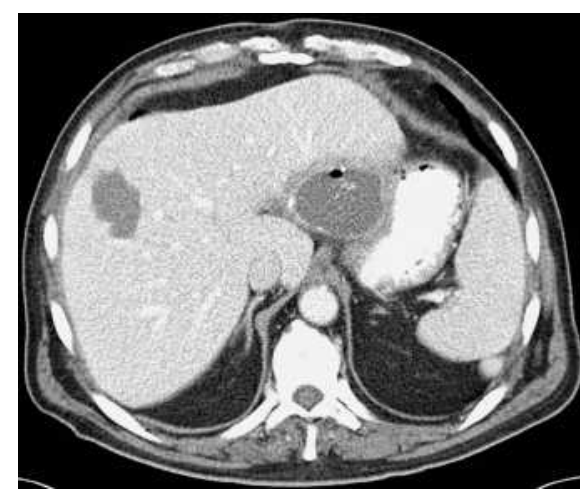

Figure 1 The computed tomogram shows a fluid collection between the liver and the stomach, causing extrinsic compression of the stomach.

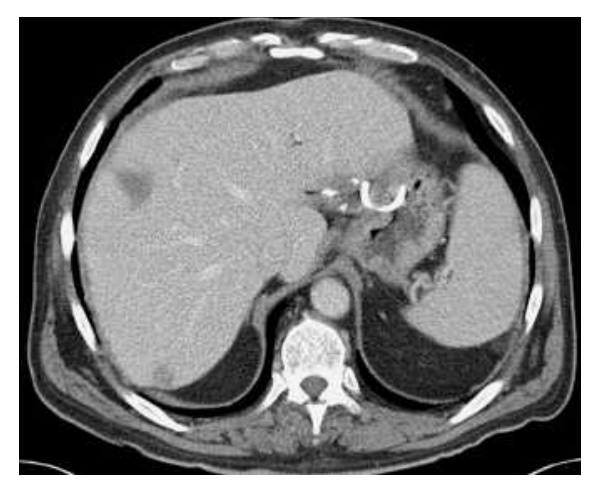

Figure 2 The follow-up abdominal computed tomogram shows resolution of the biloma, with an indwelling transgastric stent.

native to percutaneous therapy for the drainage of bilomas that are in apposition to the gastric wall.

Video A hydrophilic wire is passed transgastrically through a needle and coiled within the abscess cavity. The tract is balloon-dilated, and a 10-Fr double pigtail stent is placed.

online content including video sequences viewable at:

www.thieme-connect.de/ejournals/

abstract/endoscopy/doi/

10.1055/s-2006-925174

\section{T. H. Baron}

Department of Medicine, Division of Gastroenterology \& Hepatology, Mayo Clinic College of Medicine, Rochester, Minnesota, USA.

\section{References}

${ }^{1}$ Monkemuller KE, Baron TH, Morgan DE. Transmural drainage of pancreatic fluid collections without electrocautery using the Seldinger technique. Gastrointest Endosc 1998; 48: 195-200

${ }^{2}$ Cury MS, do Oliveira Conceicao RD, Ferrari AP. Gastric drainage of postoperative biloma. Gastrointest Endosc 2001; 54: 400-401

${ }^{3}$ Seewald S, Imazu H, Omar S et al. EUS-guided drainage of hepatic abscess. Gastrointest Endosc 2005; 61: 495-498

${ }^{4}$ Seewald S, Brand B, Omar S et al. EUS-guided drainage of subphrenic abscess. Gastrointest Endosc 2004; 59: 578-580

${ }^{5}$ Kahaleh M, Wang P, Shami VM et al. Drainage of gallbladder fossa fluid collections with endoprosthesis placement under endoscopic ultrasound guidance: a preliminary report of two cases. Endoscopy 2005; 37: $393-396$

\section{Corresponding Author}

\section{T. H. Baron, M. D., F.A.C.P.}

\section{First Street SW}

Charlton 8

Rochester

MN 55905

USA

Fax: $\quad$ + 1-507-266-3939

E-mail: baron.todd@mayo.edu 